\title{
FURTHER NOTES ON A STEEL ENERGY-ABSORBING ELEMENT FOR BRACED FRAMEWORKS
}

\author{
R. G. Tyler*
}

\begin{abstract}
The paper gives working loads and deflections for braced frameworks in which rectangular energy absorbing elements fabricated from round steel bar are incorporated to ensure reliable performance during earthquake attack. In a practical design example the locking up forces which occur for gross deformations of the system are calculated.
\end{abstract}

\section{INTRODUCTION}

The publication of the paper in the Bulletin (1) describing tests on an energy absorbing element fabricated from round steel bar and incorporated in the bracings of a framework (Fig. 1) has resulted in increased use of this type of energy absorber in structures, in particular in pole houses and small buildings. This has prompted enquiries into aspects not specifically covered in the original paper, one of which is the deflection obtained at first yield of the absorber. It will be recalled that the advantage of the system is that the progressive slack which normally develops in the bracings of a framed structure under earthquake overload does not occur when this type of element is fitted. Essentially for a rectangular frame, the inner energy absorbing frame has the same proportions as the outer framework, i.e. the line of the diagonals are coincidental.

\section{CHARACTERISTICS OF DEVICES ALREADY TESTED}

\subsection{Tests by Smith and Henry (2)}

The first tests were carried out by consulting engineers Smith and Henry in Auckland in 1978 on the frame shown in Fig. 2, for a slowly applied increasing load across one diagonal. Two $24 \mathrm{~mm}$ diameter bars were employed in the energy absorbing element, loaded by single $24 \mathrm{~mm}$ diameter bars in the main frame.

The graph of load against deflection shown in Fig. 3 was obtained. As would be expected there was a gradual departure from the straight-line characteristic from the time yield first developed on the outer limits of the sections in bending, which were located just outside the fittings transmitting the load to the corners of the rectangle. First departure from linearity is noticed at a load of about $13 \mathrm{kN}$.

* Physics and Engineering Laboratory, DSIR, Gracefield, Lower Hutt.

\subsection{Tests at PEL, DSIR}

In the tests at PEL on a square frame (Fig. 1), fabricated from $25 \mathrm{~mm}$ bars, no specific attempt was made to obtain a value for the load at first yield for a slowly applied static load. The results obtained were for cyclic testing only at $1 \mathrm{~Hz}$. Fig. 4 shows a typical set of loops obtained during the course of testing. Indications are that first yield occurred at the limits of the first narrow loop, i.e. at a load of about $5 \mathrm{kN}$. The width of this loop was probably dictated by friction effects at the pins in the rig and on the pads on which the frame rested.

3. THEORETICAL LOAD AND DEFLECTION CHARACTERISTICS FOR ROUND-BAR ABSORBERS

\subsection{Yield Condition}

For an absorber loaded across a diagonal shown in Fig. 5 by a tensile force, the moments at the corners of the frame will be equal and have a value $\mathrm{M}_{\mathrm{Y}}$. The horizontal deflection of the frame, $Y$ sy and the vertical deflection $v_{y}$ are given by:

$$
\begin{aligned}
& s_{y}=\frac{M h^{2}}{6 E I} \\
& v_{y}=\frac{M l^{2}}{6 E I}
\end{aligned}
$$

where

$E=$ The modulus of elasticity of steel $=207 \mathrm{GPa}$

$I=$ second moment of area of two round bars about a common diameter $=\pi d^{4} / 32$

Yield occurs first when

$$
\mathrm{M}_{\mathrm{y}}=2 \mathrm{f}_{\mathrm{y}} \mathrm{I} / \mathrm{d}
$$

where $f_{y}=$ the yield stress, which has a minimum value of $255 \mathrm{MPa}$ for bars to BS4360/43A up to $25 \mathrm{~mm}$ diameter. 


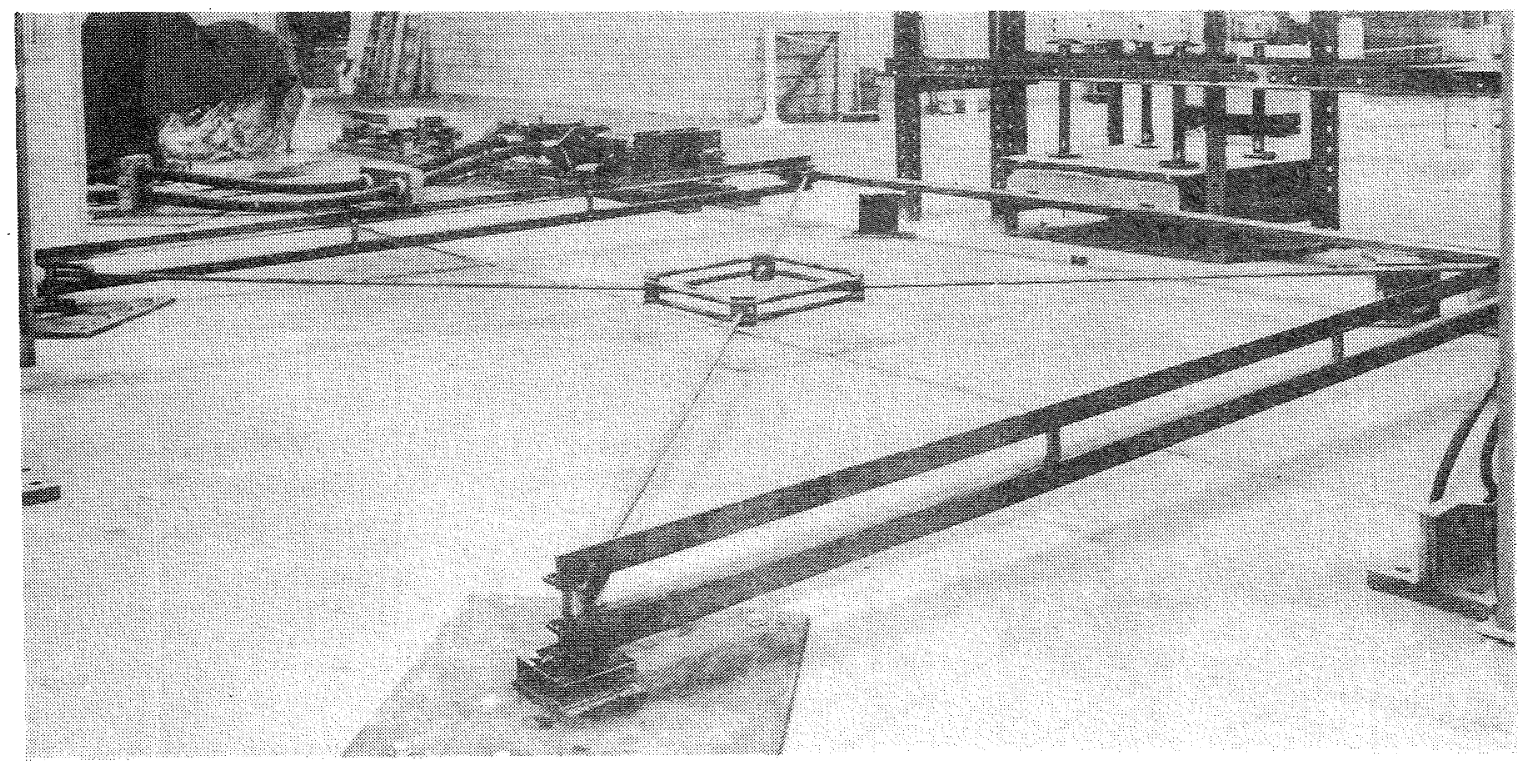

Fig 1(a) Square framework tested at PEL

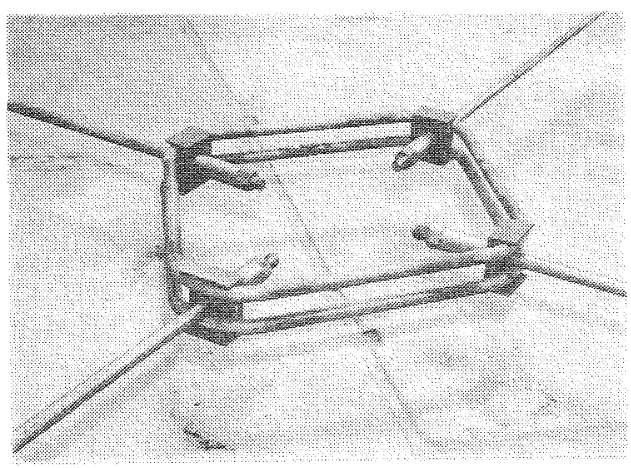

Fig I (b)

Device deformed

in plastic yield.

Load top right

to bottom left.

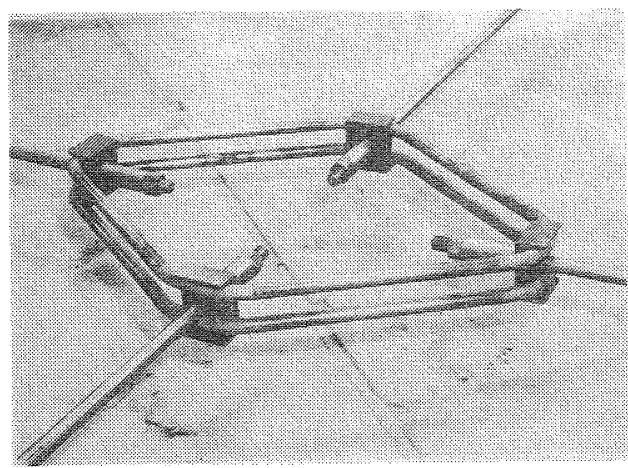

Fig $1(c)$

Load left to right. 

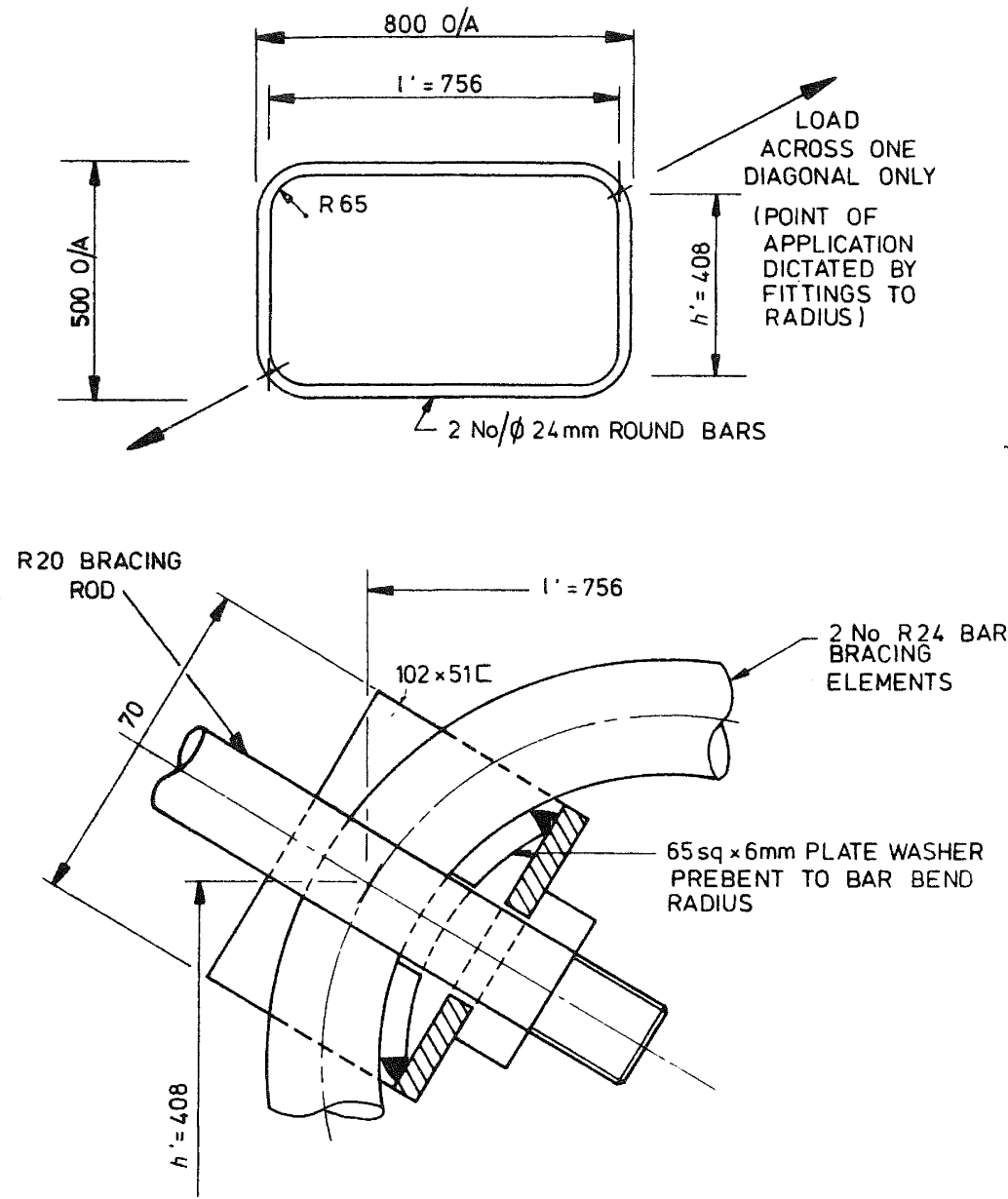

$\$ 22$ HOLE IN PLATE

AND

CHANNEL

Fig 2 Bracing absorber tested by Smith and Henry

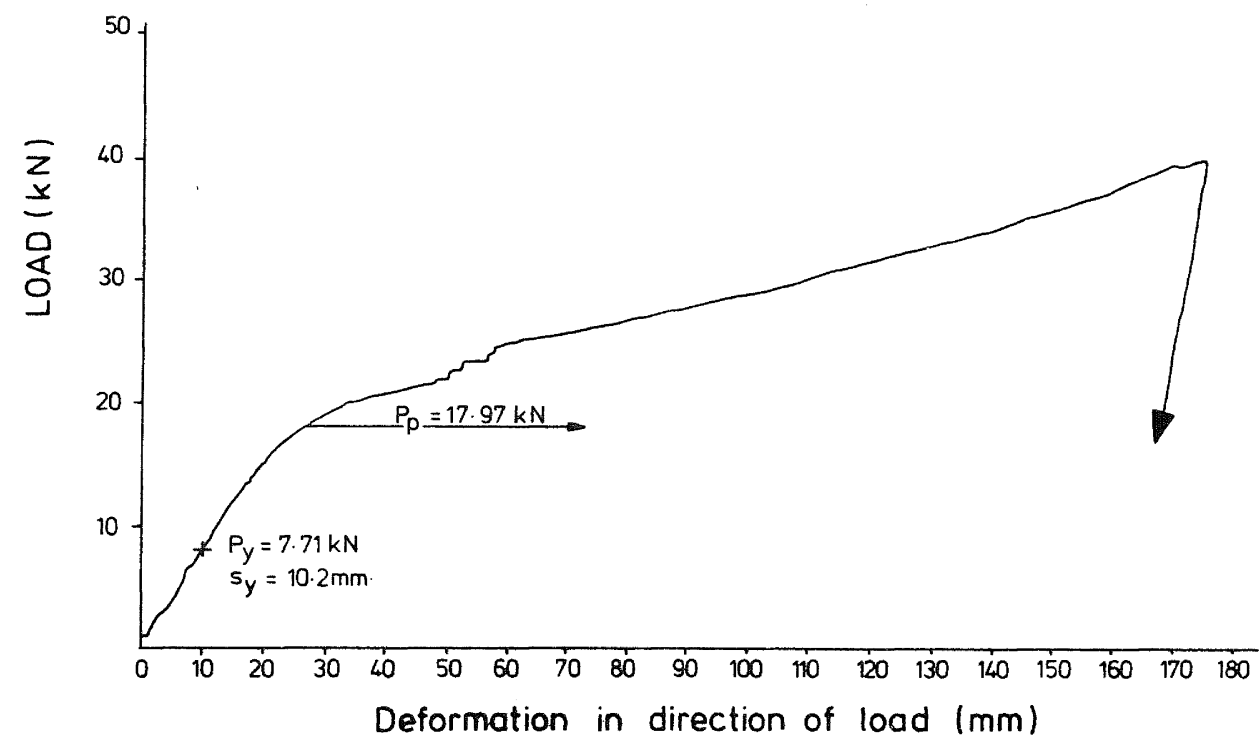

Fig 3 Load/Deflection curve for absorber tested by Smith and Henry 
Substituting

$$
\begin{aligned}
& s_{y}=f_{y} h^{2} / 3 E d \\
& v_{y}=f_{y} l^{2} / 3 E d
\end{aligned}
$$

The horizontal force $Q$ is that required to deflect the two vertical legs of length $h, i . e$.

$$
Q_{Y}=4 M_{Y} / h
$$

Also from (3) and (6)

$$
\mathrm{Q}_{\mathrm{y}}=8 \mathrm{f}_{\mathrm{y}} \mathrm{I} / \mathrm{dh}
$$

Similarly

$$
R_{y}=4 M_{Y} / \ell
$$

Substituting $\mathrm{E}_{\mathrm{f}}=255 \mathrm{MPa}$ in equations (4) and (7) respectively gives, for twin round bars

$$
\mathrm{s}_{\mathrm{Y}}=0.4106 \mathrm{~h}^{2} / \mathrm{d} \quad(\mathrm{m}), \mathrm{Q}_{\mathrm{y}}=200.3 \mathrm{~d}^{3} / \mathrm{h} \quad(\mathrm{MN})
$$

\section{2 Fully-Plastic condition}

Pursuing the concept of the plastic theory of bending, movement of the absorber is continuous when the plastic yield stress $f$ is developed across the section in bending for a shear load $Q_{p}$.

From the previous testing work $f_{p}=$ $350 \mathrm{MPa}$ was found to give meaningful
values of the shear load $Q_{\text {at }}$ atero displacement on the hysteresis loop during cyclic loading $(3,4)$, which may be taken as equal to $Q_{p}$ in this work.

The plastic modulus $K$ for two round bars bending about a common axis is given by $\mathrm{k}=\mathrm{d} / 3$. Hence the plastic moment $M_{p}=350 d^{3} / 3$. i.e.

$$
M_{p}=116 \cdot 7 d^{3} \quad M N \cdot m
$$

Also from (6) and (8)

$$
\begin{aligned}
\mathrm{Q}_{\mathrm{p}} & =4 \mathrm{M}_{\mathrm{p}} / \mathrm{h}=467 \mathrm{~d}^{3} / \mathrm{h} \\
& =\mathrm{Q}_{\mathrm{D}} \text { in design work }(3,4) . \\
\text { Also, } \mathrm{R}_{\mathrm{p}} & =4 \mathrm{Mp} / \mathrm{l}=467 \mathrm{~d}^{3} / \mathrm{l}
\end{aligned}
$$

\subsection{Effective Length of Sides of Absorber}

Preliminary calculations suggest that, to allow for the rigidity of the corner fittings at the load points, and the consequent yield of the bars outside the width of the fittings, effective lengths $l^{\prime}$ and $h^{\prime}$, which are less than $l$ and $h$ respectively, should be taken in calculation work in order to obtain meaningful estimates of the shear capacity of the absorber. In the following calculations $l^{\prime}$ and $h^{\prime}$ have been taken as the lengths between the intersection of the centre lines of the diagonals and the corner curvatures as shown in Fig. 2 .

In addition it should be noted that for rectangular frames the load points at the corners of the inner rectangle are dictated by the type of fitting employed and are usually off centre of the corner curvature (Figs. 2 and 10). The geometry is arranged such that $\mathrm{L} / \mathrm{H}=l \cdot / \mathrm{h}^{\prime}$, where $I$ is the horizontal length of the main frame and $\mathrm{H}$ the height. In practice the proportions of the sides of the rectangle should not be greater than approximately $2: 1$ as otherwise the fitting of the corner loading points becomes difficult. As cyclic testing has only been carried out on a square frame, ideally further testing should be carried out on rectangular frames to confirm their behaviour.

4. COMPARISON OF MEASURED AND CALCULATED LOADS AND DEFIECTIONS

\subsection{Absorber Tested by Smith and Henry}

\subsubsection{Yield Condition}

Substituting $h^{\prime}=408 \mathrm{~mm}, l^{\prime}=756$ $\mathrm{mm}$ (Fig. 2), $d=24 \mathrm{~mm}$, and $f=255 \mathrm{MPa}$ in equations (4) and (5) gives $\mathrm{s}_{y}=2.95$ $\mathrm{mm}$ and $\mathrm{v}_{\mathrm{y}}=9.78 \mathrm{~mm}$.

Also net deflection in the direction of the diagonal =

$$
\begin{aligned}
& \sqrt{\mathrm{s}_{y}^{2}+v_{y}^{2}}=10.2 \mathrm{~mm} \\
& \text { Using (3) } \mathrm{M}_{\mathrm{y}}=692 \mathrm{Nm} \\
& \text { (6) } \mathrm{Q}_{\mathrm{Y}}=6.78 \mathrm{kN} \\
& \text { (7) } \mathrm{R}_{\mathrm{y}}=3.66 \mathrm{kN}
\end{aligned}
$$

Net diagonal force $P_{Y}=\sqrt{Q_{y}^{2}+R_{y}{ }^{2}}$

$$
=7.71 \mathrm{kN}
$$

This value is shown as point $P$ on Fig. 3. Evidently the yield stress of the material was higher than the minimum specified value of $255 \mathrm{MPa}$ used in the calculation as the straight portion of the curve continues up to about $13 \mathrm{kN}$.

\subsubsection{Plastic Condition}

For the fully plastic condition causing continuous movement:

$$
\begin{array}{rlrl}
\text { From } & (10) \mathrm{M}_{\mathrm{p}} & =1.613 \mathrm{kNm} \\
" \quad(11) & \mathrm{Q}_{\mathrm{p}} & =15.81 \mathrm{kN} \\
" \quad(12) & \mathrm{R} & =8.53 \mathrm{kN} \\
\text { and } & & \mathrm{P}_{\mathrm{p}} & =\sqrt{\mathrm{Q}_{\mathrm{p}}^{2}+\mathrm{R}_{\mathrm{p}}^{2}}=17.97 \mathrm{kN}
\end{array}
$$

This value is shown on Fig. 3 and is seen to indicate alower value for the load 


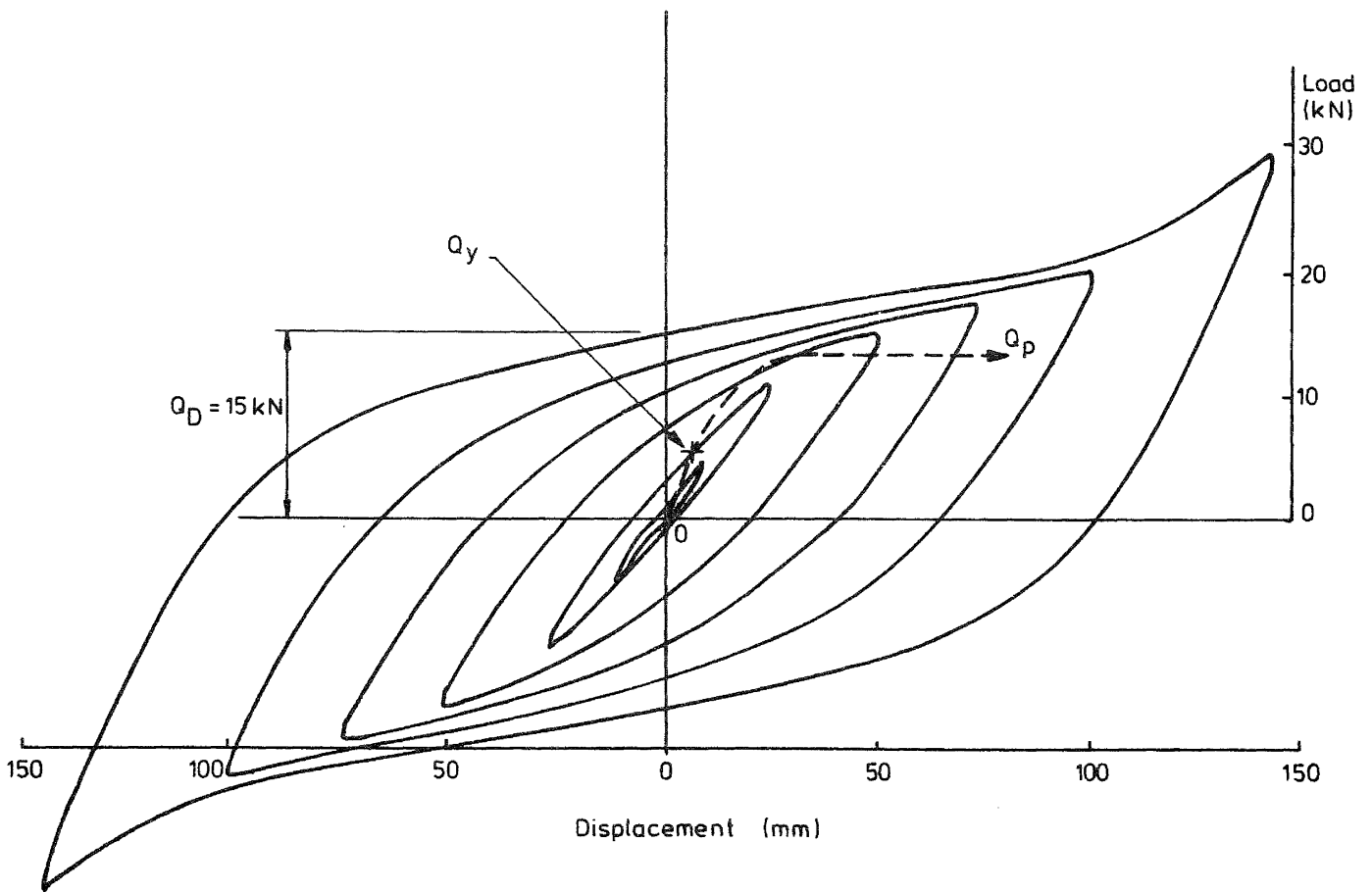

Fig. 4 Hysteresis loops for square device tested at PEL

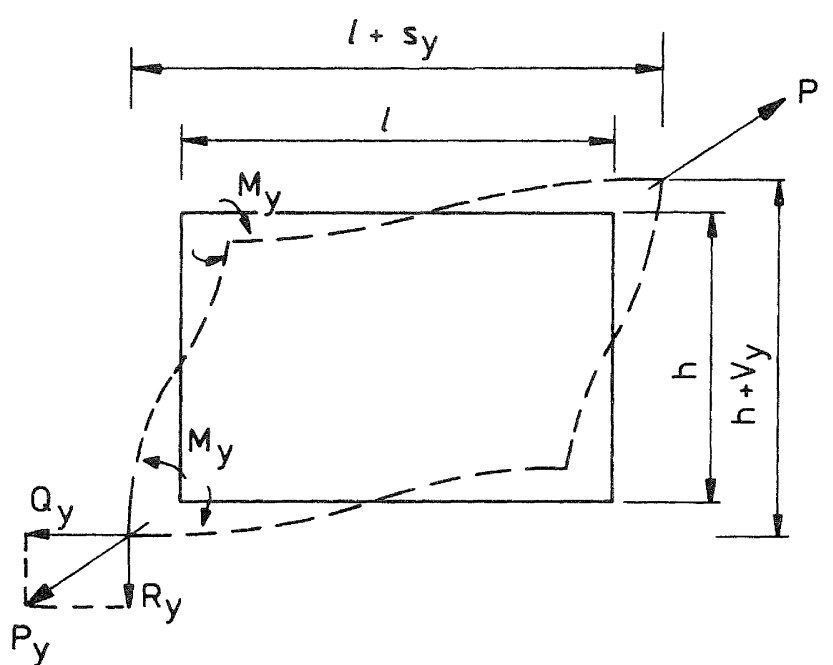

Fig 5 Deflections at yield for energy. absorbing element 
required to propogate continuous movement.

\subsection{Absorber Tested at PEL, DSIR}

\subsection{Yield Condition}

Fig. 6 .

The absorber details are shown in

$$
\ell^{\prime}=h^{\prime}=552 \mathrm{~mm}
$$

Substituting in equations (4) and (5) for $f=255 \mathrm{MPa}$, gives for the first yield condition:

$$
\mathrm{s}_{y}=v_{Y}=5.0 \mathrm{~mm}
$$

This motion, together with additional motion to accommodate the deflection of diagonal rods, pins, etc. will be required at the jack to start yield.

Using (3)

Using

(6) \& (8)

$$
M_{Y}=7.823 \times 10^{-4} \mathrm{MN} \cdot \mathrm{m}
$$$$
Q_{Y}=R_{Y}=5.669 \mathrm{kN}
$$

This load gives the straight line oQy in Fig. 4 for the deflection up to $5 \mathrm{~mm}$. This is a stiffer characteristic than that recorded in the tests, but bearing in mind that deflections were measured by a transducer in the jack ram and would include flexibilities of rods, pins, ram, etc. up to the jack, the characteristic is not unreasonable. The value of yield load appears to be approximately correct as a narrow loop would be obtained at that load, the loop width being attributable to friction in the pins and on bearing pads supporting the frame weight.

\subsubsection{Plastic Condition} $1.823 \mathrm{kN} \cdot \mathrm{m}$ Using equation (10) $\mathrm{M}_{\mathrm{p}}=116.7 \mathrm{~d}^{3}=$
$\mathrm{kN} \cdot \mathrm{m}$ From (11) and (12) $Q_{\mathrm{p}}=\mathrm{R}_{\mathrm{p}}=4 \mathrm{Mp} / \mathrm{h}=$
$13.2 \mathrm{kN}$.

This is indicated by the line QP in Fig. 4 and is seen to be a conservative estimate of the load required to cause plastic yield.

\subsection{Conclusions}

(1) The calculated values of horizontal deflection for first yield in the absorber, $s$, as given by equation (4) agrees yeasonably well with the test results when the yield stress of $255 \mathrm{MPa}$, quoted as the minimum permissible for bars to BS $4360 / 43 \mathrm{~A}$ up to $25 \mathrm{~mm}$ diameter, is used.

(2) The shear load $Q$ at first yield calculated from equation ( 9 ) also agrees reasonably well with the test results.

(3) The value of the shear load $Q$ to cause continuous movement of the joint of the absorber, as calculated from equation (11), gives a conservative estimate of the load capacity of the absorber.

\section{DESIGN CURVES}

5.1 Design Curves for Range of Shear Loads for Energy Absorption

Values of the shear load at yield, Qy, from equation ( 9 ) and the shear load for the fully plastic condition, $Q$, from equation (Il), are plotted for a renge of bar sizes in Fig. 7, to indicate the design range of loading for energy absorption. Above $Q_{p}$ the number of cycles to failure is redueed and a locking up condition may develop.

\subsection{Design Curves for the Range of Deflections Associated with Energy Absorption}

\section{2 .1 Yield Condition}

The deflection $s_{y}$ associated with first yield, obtained fyom equation (9), is shown plotted in Fig. 8 for a range of bar sizes.

\subsubsection{Deflection Associated with Plastic Condition}

Since the plastic theory of bending in its simplest form associates continuous yielding at the plastic yield stress $f$ with no limit on deflection, resort has ${ }^{p}$ to be made to practical testing in order to assess the likely deflection at peak energy absorption.

In the tests at PEL a jack motion of $100 \mathrm{~mm}$, giving an overall frame deformation,

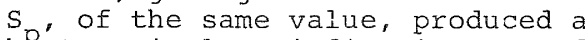
hysteresis loop indicating a good absorption of energy; from previous testing this would correspond to a strain of about $3 \%$ at the extremes of the section of the bar in bending $(3,4)$. For the square of $610 \mathrm{~mm}$ side, the angular rotation of each joint is given by sin-1 100/610, i.e. $9.4^{\circ}$, on the assumption that the shear

deformation in the inner and outer squares has approximately the same value, which is true for small angles of rotation (see calculation para. 6.2 for an example of actual values).

If the size of the inner rectangle is reduced relative to the outer, then less shear deflection is required to produce the same angular rotation and the same energy absorption, i.e. the device becomes stiffer. By proportion, for the same energy absorption the deflection for an absorber of height $h$ is given by $s_{p}=0.1 \mathrm{~h} / 0.61$ metres.

Also previous testing has indicated that a good energy absorption and a reasonable life is obtained for a strain of $3 \%$ at the extremes of the section. Evidently this strain is reached more rapidly as the bar size increases. On the assumption that plane sections remain plane, then the most desirable shear deflection for bars of diameter $d$, when compared with $25 \mathrm{~mm}$ bars used in the test, is given approximately by: 


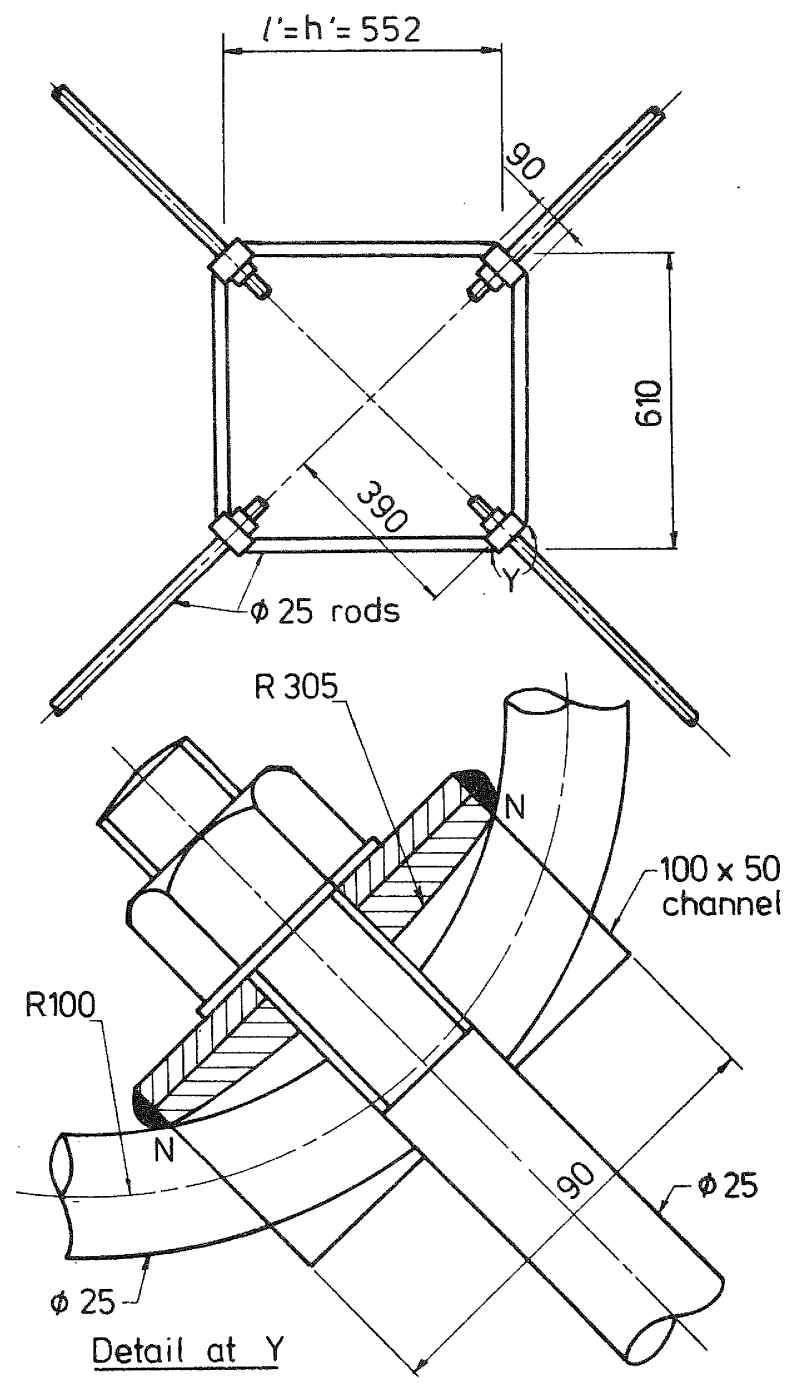

Fig. 6 Details of Absorber tested at PEL

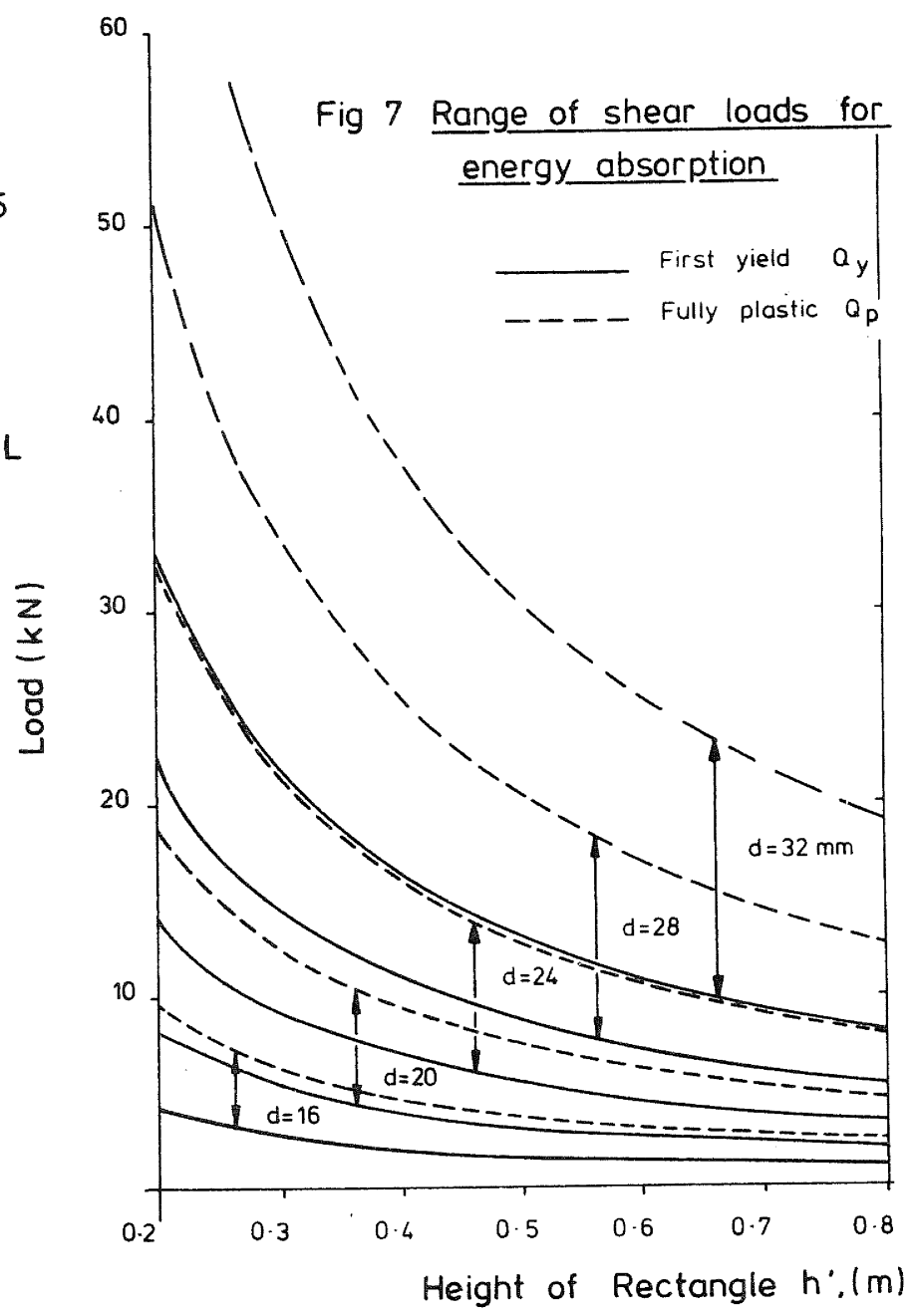




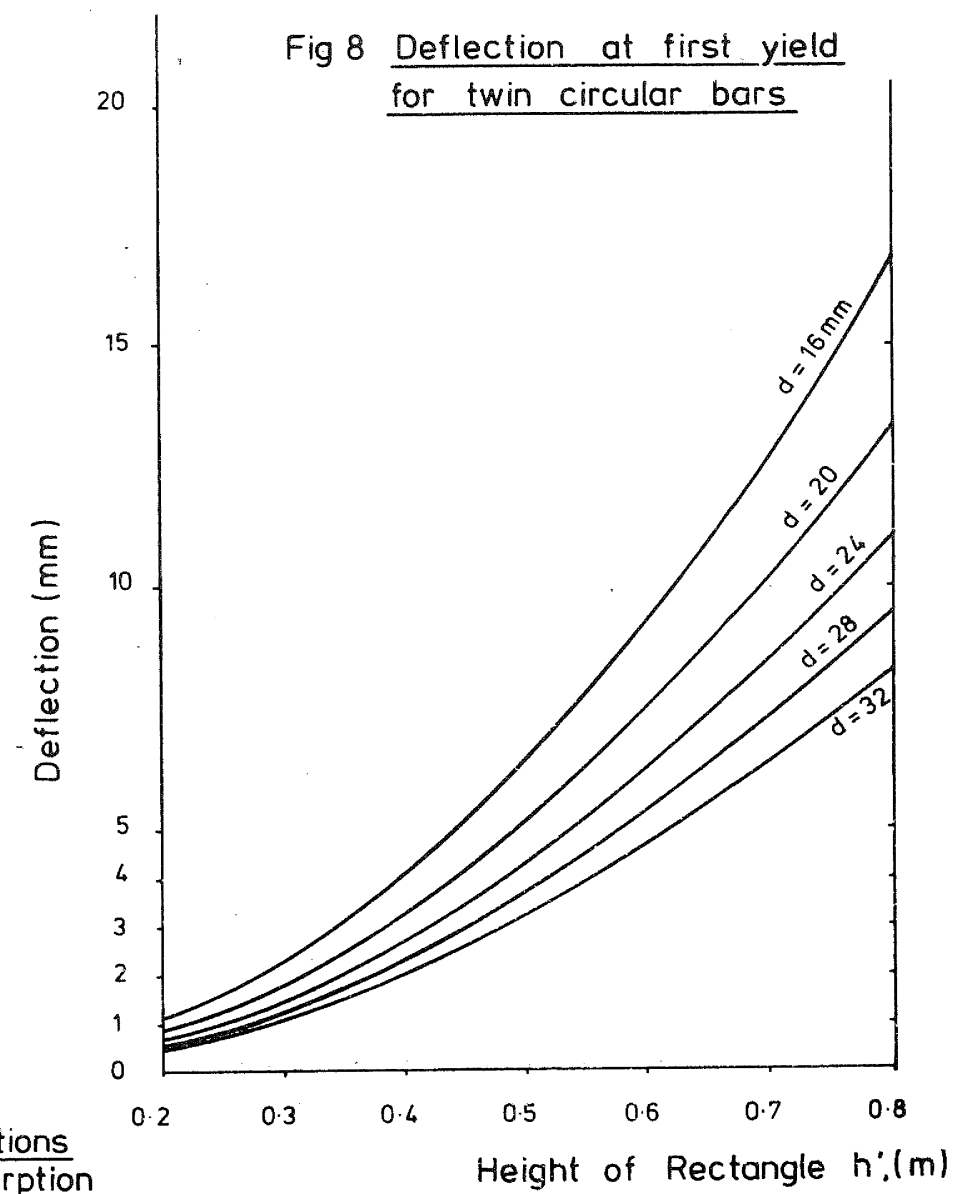

Fig $9 \frac{\text { Range of deflections }}{\text { for energy absorption }}$

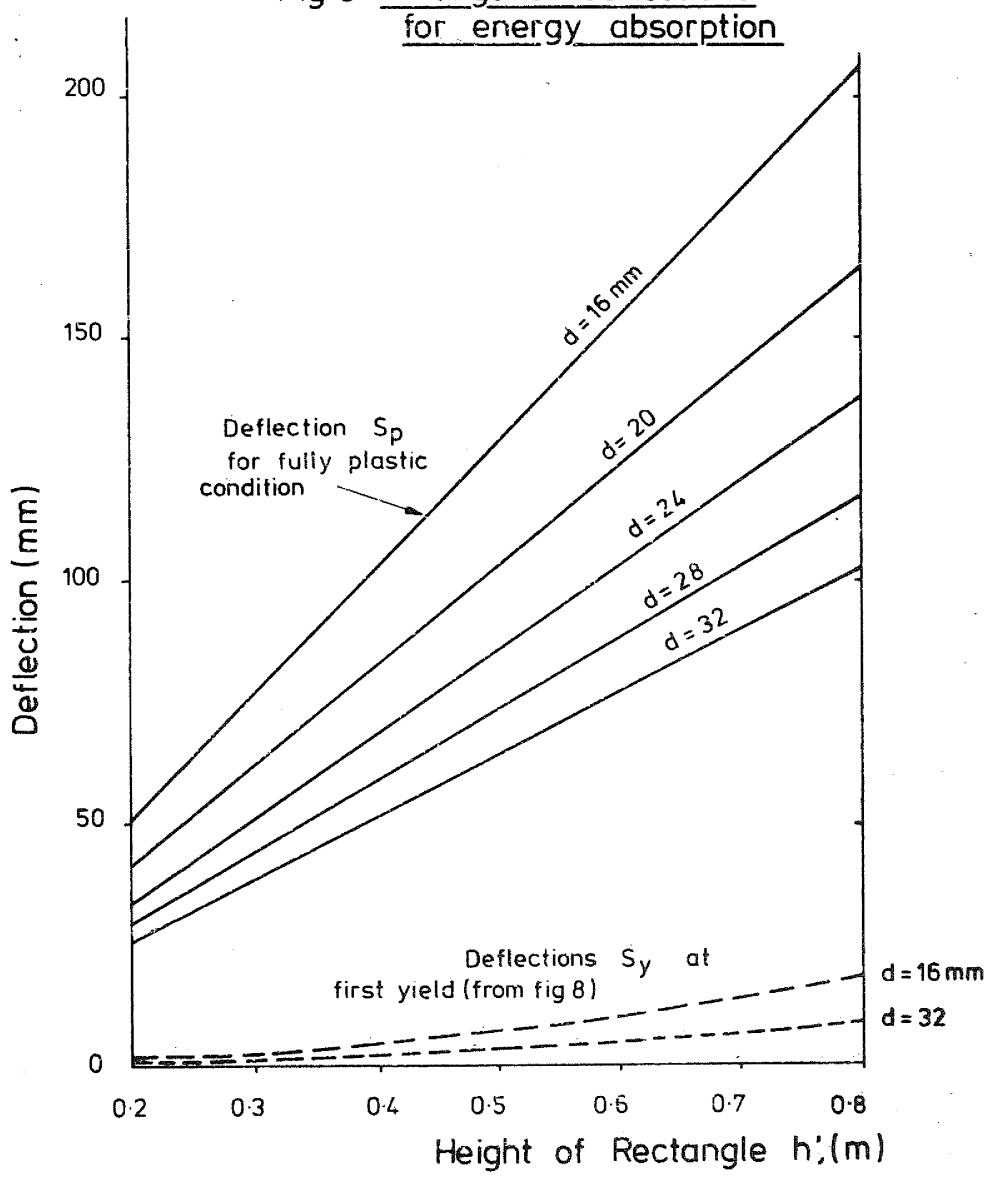




$$
\begin{aligned}
s_{n} & =0.1 \mathrm{~h} \times 0.025 / 0.61 \mathrm{~d} \\
\text { i.e. } s_{p} & =4.1 \mathrm{~h} / \mathrm{d} \mathrm{mm} \cong \mathrm{s}_{p}
\end{aligned}
$$

This relationsintp is shown plotted in jig. 9 for a cange of bar sizes and gives a rough indication of the deflecticn required to produce good energy absurption. The deflections $S$ at first yield are replotted from Fig. $8^{Y}$ in Fig. 9 by way of conparisor, and the deflections for the fully plastic condition are seen to be up to 50 times those at first yield, this value being approached when both the bar size and the height of the rectangle are comparatively smali, i.e. $d=16 \mathrm{~mm}$ and $h^{\prime}=0.2 \mathrm{~m}$.

\section{LOCK-UP CHARACTERISTICS \\ 6.1 General}

Lock-up of the bracing occurs for gross deformation of the central rectangle when the geometric shortening of the diagonal dimension in the unloaded direction is significantly greater than that of the corresponding diagonal dimension of the outer rectangle. In the tests on the square frame at PEL, lock-up began when the lateral deflection of the jack reached $\pm 142 \mathrm{~mm}$ (see Fig. 4), corresponding roughly to a rotation strain of $\sin ^{-1} 142 / 610$, i.e. about $13^{\circ}$, in the twin $25 \mathrm{~mm}$ bars. At the working deflection of $\pm 100 \mathrm{~mm}$, corresponding to about $9^{\circ}$, there was negligible lock-up.

Since deflections are designed to be less as the size of bar increases (Fig. 9) there is less chance of lock-up if larger bars are chosen. However, in general, the problem does not appear to be one of practical significance as in the examples calculated so far optinum energy absorption occurs before lock-up. In the tests carried out at PEL, the lock-up stresses did not cause overstress ana a further example of the calculation, for a practical design, is given below.

\subsection{Calculation of Lock-Up Forces for a Typical structure}

The bracing shown in Fia. 1.0 was installed in a building by consultants Whitcher, Grant, King and Associates of Lower Hutt, the effective lengths of the absorber sides beina $\ell^{\prime}=480$ and $h^{\prime}=$ $290 \mathrm{~mm}$ as shown for a pair of $20 \mathrm{~mm}$ rods. Also $\mathrm{L}=4.8 \mathrm{~m}$ and $\mathrm{H}=2.9 \mathrm{~m}$.

Following through the design,

Horizontal deflection $s_{y}$ at first yield (Fig. 8 and equation 9) ${ }^{\mathrm{S}}=1.726 \mathrm{~mm}$.

Horizontal deflection $\mathrm{Sp}$ for peak energy absorption $=59.45 \mathrm{~mm}$ (Fig. 9 and equation (13).

Lateral load Qy at first yield (Fig. 7 and equation $9^{\prime}$ ) $=5.53 \mathrm{kN}$.

Lateral load Qp for peak energy absorption (Fig. 7 and equation II) = $12.88 \mathrm{kN}$.
For the calculation of lock-up effects:

Extension of outer frame diagonal = $D_{t}-D_{0}$

$$
=\sqrt{L^{2}+\mathrm{H}^{2}+2 L S_{p}}-\sqrt{L^{2}+\mathrm{H}^{2}}
$$

Substituting values:

Extension of Erame diagonal $=50.685 \mathrm{~mm}$

The extension of the outer frame diagonal is imposed as the change of dimension on the corresponding inner frame diagonal dimension.

i.e. $\sqrt{l^{2}+h^{2}+2 l s_{p}}-\sqrt{l^{2}+h^{2}}=50.69 \mathrm{~mm}$

Substituting values gives $\mathrm{s}_{\mathrm{p}}=61.89 \mathrm{~mm}$, i.e. about $2 \mathrm{~mm}$ more than the corresponding shear deflection of the outer frame, $s_{p}$.

The shortening of the compression diagonal of the outer frame is given by

$$
\sqrt{\mathrm{L}^{2}+\mathrm{H}^{2}}-\sqrt{\mathrm{L}^{2}+\mathrm{H}^{2}-2 L S_{\mathrm{p}}}=.051087 \mathrm{~m}
$$

The corresponding shortening of the inner Erame is given by

$$
\sqrt{l^{2}+h^{2}}-\sqrt{l^{2}+h^{2}-2 \ell s_{p}}=.055740 \mathrm{~m}
$$

The difference in shortening $=\mathrm{G}=4.653 \mathrm{~mm}$

Neglecting direct strain within the inner rectangle this extension will be accommodated by strains in the diagonal rods, each having a length of $5.047 \mathrm{~m}$, with some adjustment of the geometry of the framework. The self-straining stress $\mathrm{f}_{\mathrm{S}}$ will be given by

$$
\begin{aligned}
\mathrm{f}_{\mathrm{S}} & =\mathrm{E} \times \text { strain } \\
& =207000 \times 4.653 / 2 \times 5.047 \times 10^{3} \\
& =95.4 \mathrm{MPa}
\end{aligned}
$$

The working load $Q$ of $12.88 \mathrm{kN}$ will add a further $41.0 \mathrm{MPa}$ to the stress in the tensile diagonal giving a total stress of 136.4 MPa, which is well within the minimum yield stress of the material at $255 \mathrm{MPa}$.

\section{CONCLUSIONS}

The bracing method proposed is an extremely reliable way of providing earthquake resistance in structural panels in that testing (1) showed that many hundreds of cycles of loading could be completed repetitively without the development of slack in the bracing rods.

The design shear loads $Q_{p}$ for large deformation (Fig. 7 ) are $p$
conservative in that the work hardening conservative in that the work hardening peak shear loads above the values given on the graph. 
The range of deflections (Fig. 9) enable an estimate to be made of whether a particular bar size is acceptable from the point of view of inter-storey drift.

A locking-up effect occurs for gross deformation but this will normally be outside the range of contemplated design work. However as this effect is often used in snubbers, shock absorbers, boat fenders, etc. it can be designed for, if required, by allocating sufficient area in the bracing rods to carry the direct tensile forces involved.

\section{REFERENCES}

(1) Tyler, R.G., "Preliminary Tests on an Energy Absorbing Element for Braced Structures Under Earthquake Loading", Bulletin of the N.Z. National Society for Earthquake Engineering, Vol. 16, No. 3, september 1983, pp. 201-212.

(2) Smith, D.C. and Henry, R.W. "Diagonal Brace Energy Absorber". Private Communication, April 1981.

(3) Tyler, R.G., "Tapered Steel Cantilever Energy Absorbers" Bulletin of the N.Z. National society for Earthquake Engineering, Vol. 11, No. 4, December 1978, pp.282-294.

(4) Tyler, R.G., "A Tenacious Base Isolation System Using Round Steel Bars", Bulletin of the N.Z. National Society for Earthquake Engineering, Vol. 11, No. 4, December 1978 . pp. 273-28I.

9. NOTATION

$M=$ bending moment

$M_{y}=$ bending moment at yield of the absorber bars

$M_{p}=$ bending moment for plasticity in absorber bars

$\mathrm{H}=$ height of main frame

$\mathrm{h}=$ height of inner rectangular device

$h^{\prime}=$ effective height of inner rectangular device

$L=$ length of main frame

$\ell=$ length of inner rectangular device

$\ell^{\prime}=$ effective length of inner rectangular device

$\mathrm{E}=$ modulus of elasticity

$I=$ second moment of area of bars of inner device

$\mathrm{f}=$ stress in bending

$f_{y}=$ yield stress in bending

$f_{p}=$ plastic stress for mild steel

$\mathrm{P}=$ load in diagonal to cause bending of inner rectangle

$P_{y}=$ ditto at yield

$\mathrm{d}^{\mathrm{y}}=$ diameter of round steel bars

Sy $=$ shear deflection of outer frame at first yield
$s_{Y}=$ shear deflection of inner frame at first yield

$s_{p}=$ shear deflection of outer frame for plastic flow

$s_{p}=$ shear deflection of inner frame for plastic flow

$v_{y}=$ vertical deflection of inner frame at first yield

$Q$ = lateral shear loading

$Q_{p}=$ lateral shear loading for plasticity of absorber

Note: $Q_{p}$ may be taken as $Q_{D}=$ lateral shear load for zero displacement of hysteresis loop, used in design work $(1)$

$\mathrm{R}=$ vertical loading induced in absorber corresponding to $S$

$R_{Y}=$ vertical loading induced in absorber at $y$ ield corresponding to $\mathrm{S}_{\mathrm{y}}$

$R_{p}=$ vertical loading induced in absorber at plasticity corresponding to $s_{p}$

$\mathrm{K}=$ plastic modulus for bars of absorber

$D_{0}=$ original diagonal length of outer frame

$D_{t}=$ extended diagonal length of outer frame.

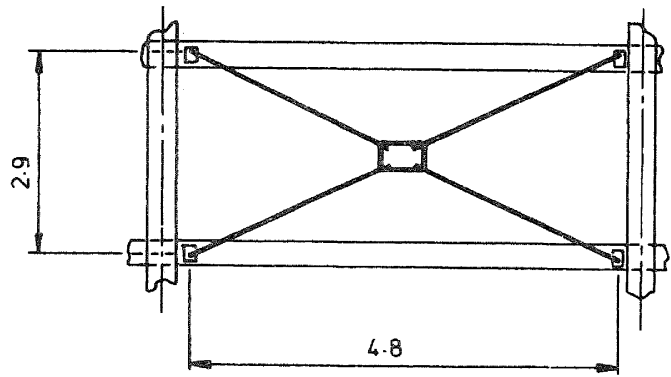

Fig 10a Elevation of Bracing. in building.

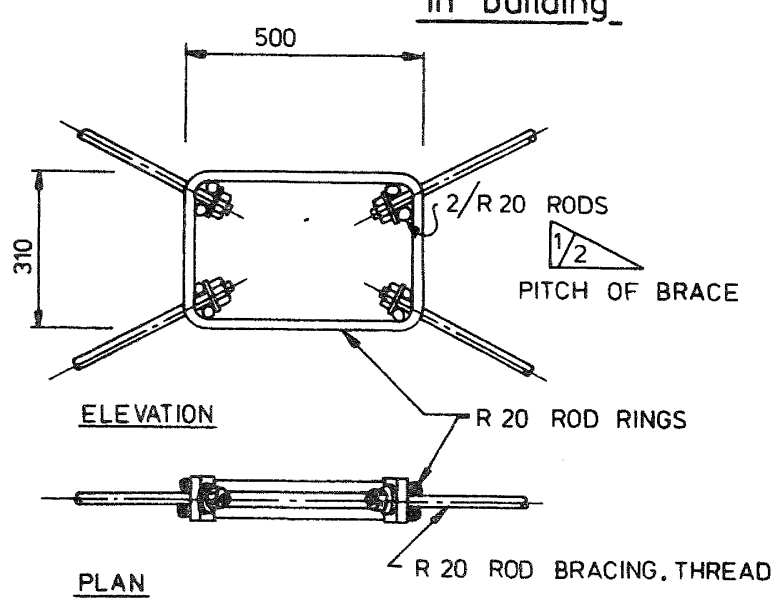

Fig $10 \mathrm{~b}$ Details of absorber element 